\title{
Participation of natural resource managers on editorial boards of conservation and applied natural resource journals
}

\author{
Sarah K. CARTER and Andrew H. Fayram
}

\begin{abstract}
A gap between research and management exists in numerous natural resource fields. This can lead to management actions that are based on experience rather than evidence and may be less effective as a result. The gap may be partly attributable to research not being relevant, timely or accessible for managers. Editorial boards of peer-reviewed journals are responsible for determining the relevance of submitted manuscripts for a journal's readership. Limited representation of natural resource managers on editorial boards may make it more difficult for journals to identify the topics and findings of most relevance for management, thus contributing to the research-management gap. We quantified the representation of natural resource managers on the editorial boards of 79 conservation and applied natural resource journals. We found that $65 \%$ of editors were affiliated with universities, $13 \%$ with research institutions, $12 \%$ with government agencies and $3 \%$ with NGOs. On average, $9 \%$ of editors were affiliated with an agency or organization responsible for managing or regulating natural resources. The proportion of managers on editorial boards did not differ significantly between natural resource fields or with journal impact factor. Potential benefits of greater integration of managers into the research and publishing process include selection of research topics with greater relevance for management, clearer statements of the management implications of research studies, and more frequent publication of research evaluating the effectiveness of management interventions. Further study is needed to evaluate whether greater participation of managers in the editorial review process may contribute to achieving these benefits.
\end{abstract}

Keywords Editorial review process, evidence-based conservation, natural resource management, natural resource policy, research-management gap, scientific publication process

To view supplementary material for this article, please visit http://dx.doi.org/10.1017/So030605315001465

SARAH K. CARTER ${ }^{*}$ (Corresponding author) SILVIS Lab, Department of Forest and Wildlife Ecology, University of Wisconsin-Madison, 1630 Linden Drive, Madison, WI 53706, USA. E-mail skcarter@usgs.gov

Andrew H. Fayram Department of Fish, Wildlife and Conservation Biology, Colorado State University, Fort Collins, USA

${ }^{*}$ Current address: U.S. Geological Survey, Fort Collins Science Center, 2150 Centre Ave. Building C, Fort Collins, CO 80526-8118, USA

Received 24 June 2015. Revision requested 16 September 2015. Accepted 23 December 2015. First published online 18 April 2016.

\section{Introduction}

Tatural resource managers play a critical role in conser1 vation and sustainable use of natural resources. However, management often does not incorporate the findings of peer-reviewed research (Pullin \& Knight, 2005; Cook et al., 2010; Cvitanovic et al., 2014), nor does research often target the specific questions that managers need answered (Fazey et al., 2005). Less than half (37\%) of studies published in prominent conservation journals are considered highly relevant for management, and only $20 \%$ are considered highly relevant for policy (Fazey et al., 2005). More recent findings underscore this mismatch between research topics and management needs, with only $19 \%$ of published articles on marine protected areas considered relevant for marine protected area management (Cvitanovic et al., 2014). Poor information-sharing between research and management hampers implementation of evidence-based conservation (Sutherland et al., 2004), which can lead to ineffective management actions and inefficient use of resources (Walsh et al., 2012). The gap between research and management (Meffe, 1998; Pullin et al., 2004) also presents challenges for managing resources according to the best available science, as required by many federal environmental laws (Sullivan et al., 2006).

There are a number of possible reasons for the researchmanagement gap, including science that is not timely, science that is difficult and time-consuming for managers to access and read, and science for which policy and management implications are not clear (Fazey et al., 2005; Pullin \& Knight, 2005; Seavy \& Howell, 2010; Cvitanovic et al., 2014; Matzek et al., 2014). Researchers and managers/policy makers often operate under different demands and constraints, and are accountable to stakeholders with different perspectives and goals (e.g. federal funding agencies vs local recreational interest groups), which may result in different timelines for action, different foci and methods for gathering information, different outlets for sharing information, and different incentive and reward structures (Gibbons et al., 2008; Born et al., 2009; Fayram et al., 2009; Gossa et al., 2015). All of these factors may contribute to maintaining a gap between research and management.

We asked whether the publication process for peerreviewed literature, in particular the composition of editorial boards, could also be contributing to a disconnect between researchers and managers. Among the roles and responsibilities of editorial boards (including editors-in-chief) of scientific, 
peer-reviewed journals are to evaluate submitted manuscripts for appropriateness of content to the readership of the journal, recommend which manuscripts should be sent for peer review, and advise the journal on long-term goals, content and mission (Scott-Lichter et al., 2012). As such, the editorial board has considerable authority to determine which manuscripts are deemed suitable for publication in both the near and longer term.

Decisions to send a manuscript for review are most commonly based on an editor's perception of the relevance of the topic and conclusions to the readership of the journal. Important technical details such as study design, statistics and ecological theory are also considered. We suggest that an editorial board member's affiliation may influence their perception of the relevance of a particular topic to the journal's mission. In particular, we suggest that individuals whose current position involves making decisions about natural resource conservation, management or policy may be the best judges of the relevance of topics for conservation and resource management in practice.

Our goal was to determine whether managers and policy makers are currently involved in making editorial decisions for journals that explicitly target the application of research to conservation, management or policy actions. Our first objective was to describe the composition of editorial boards of conservation and applied natural resource journals. We asked to what extent editorial boards include professionals outside universities and with formal authority or responsibility for natural resource conservation, management or policy (hereafter, management authority). An editorial board composed of members from various types of institutions and organizations may provide a broader foundation for evaluating the conservation and management relevance of submitted manuscripts. Our second objective was to assess differences by field (e.g. fisheries, zoology) and journal impact factor in the prevalence of board members affiliated with agencies or organizations with formal management authority. We hypothesized that fields with a more direct link to commercial harvest or applications (e.g. forestry, fisheries, entomology) and journals with lower impact factors (which often have a more regional focus and thus potentially coincide more with the interests and expertise of many natural resource managers) might have more managers on their editorial boards.

\section{Methods}

\section{Journals}

We identified conservation and applied natural resource journals using the ISI Web of Science Journal Citation Reports database for 2013 (Thomson Reuters, 2013). We selected journals in 16 subjects: biodiversity conservation, biology, ecology, entomology, environmental sciences, fisheries, forestry, limnology, marine and freshwater biology, oceanography, ornithology, plant sciences, soil science, water resources and zoology. We identified a subset of these journals that we expected to have an explicit focus on the application of research to conservation, management or policy, on the basis that the title or subtitle included one or more of the following words: applied or application, conservation, management, practice or policy. We refer to this group as applied natural resource journals $(n=109$, Supplementary Table $\mathrm{S}_{1}$ ).

Journals may be categorized under more than one subject in the database (25 of the 109 applied natural resource journals were listed under multiple subjects). We deleted duplicate records of the same journal by retaining the subject category that most closely reflected the journal's title, aim and scope (e.g. the journal Biodiversity and Conservation was categorized in the database as biodiversity conservation, ecology and environmental sciences; we retained the biodiversity conservation categorization).

\section{Editorial boards}

During 19 December 2014-16 November 2015 we identified members of the editorial board of each applied natural resource journal from the journal's website. We categorized members as either chief editor or other editorial board member (e.g. associate, science, subject editor). Most journal websites listed the affiliations of all editorial board members, but in a few cases the affiliations of some editors were not included. In these cases we searched the internet and recent published literature, starting with the name of the editor and the journal topic, to identify current affiliations. We did not consider technical, assistant, founding, honorary, managing, consulting or book-review editors, as these do not normally play a role in identifying the suitability of the topic of a submitted manuscript for publication in the journal. We omitted five of the 109 applied natural resource journals from our evaluation because their websites did not list editorial board members (Supplementary Table S1).

We categorized the affiliation of each editorial board member as university (including colleges and other educational institutions of higher learning), research institution (including federally funded research institutions and NGOs specifically named or described as research institutions), federal agency, regional/state/local agency, intergovernmental organization/commission, NGO, professional association, private company/consultant, park, zoo/aquarium, museum, botanical garden, or no affiliation. Furthermore we identified whether agencies, intergovernmental organizations/commissions and NGOs owned or had authority for managing natural areas and/or regulating natural resources, based on their mission and specific 
activities listed on their websites (e.g. The Nature Conservancy, an NGO, owns and manages many natural areas; the U.S. Geological Survey, a federal agency, conducts research relevant to many conservation and management questions but does not manage or regulate natural resources).

\section{Analysis}

We stratified the applied natural resource journals by subject and by the 2013 journal impact factor (impact factor $<2$ or $\geq 2$ ), and randomly sampled a maximum of five journals in each subject/impact factor category (often categories contained fewer than five journals). Our final sample size was 79 journals, representing 84 journals chosen in the random sample minus five journals for which editors were not listed on the journal website. For each journal we assessed the composition of the chief editor(s) and the editorial board. We also calculated the representation of non-university organizations and of organizations with formal management authority among chief editor(s) and the entire editorial board. Finally, we assessed differences by subject and journal impact factor in the prevalence of board members affiliated with non-university organizations and with organizations with management authority. We considered only subjects with at least one journal in each impact factor category, and tested for differences using twoway ANOVA $(\alpha=0.05)$.

\section{Results}

On average we categorized $12 \%$ of journals in each subject as applied natural resource journals (range 1-45\%, Fig. 1). These 109 journals with a clear and stated focus on the application of findings to natural resource management, conservation or policy were the foundation for our study. Ninety-nine percent of these conservation and applied natural resource journals that we sampled included at least one non-university member on the editorial board. Of the 2,793 editorial board members we evaluated, $65 \%$ were affiliated with universities, $13 \%$ with research institutions, $12 \%$ with government agencies, $4 \%$ with private companies, and $3 \%$ with NGOs (Fig. 2). Most (89\%) agency affiliates were from federal rather than regional, state or local agencies. Fifty-five percent of editors affiliated with a federal agency worked for an agency that does not have management authority. Of those editors affiliated with a U.S. federal agency $(n=144), 26 \%$ worked for the U.S. Department of Agriculture-Agricultural Research Service, $22 \%$ each for the U.S. Geological Survey and the U.S. Forest Service, and $8 \%$ for the National Marine Fisheries Service.

We found similar overall patterns for chief editors (Fig. 2). Overall, 66\% of chief editors were affiliated with a

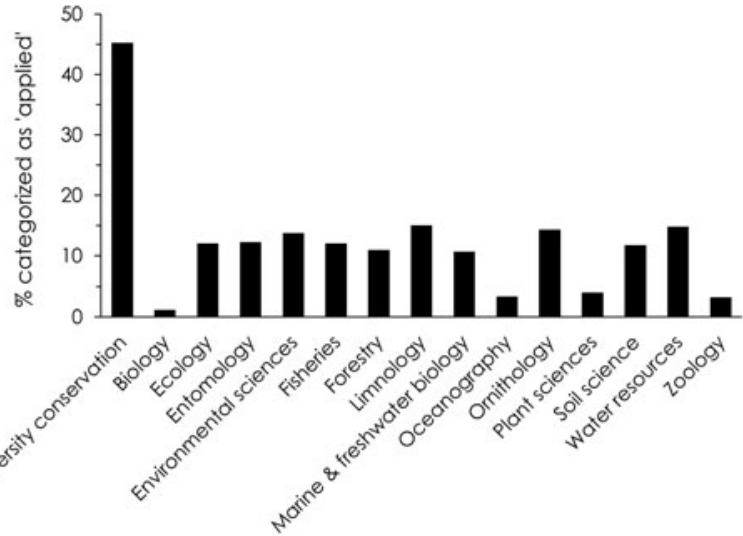

FIG. 1 Percentage of journals categorized as applied within each natural resource subject category.

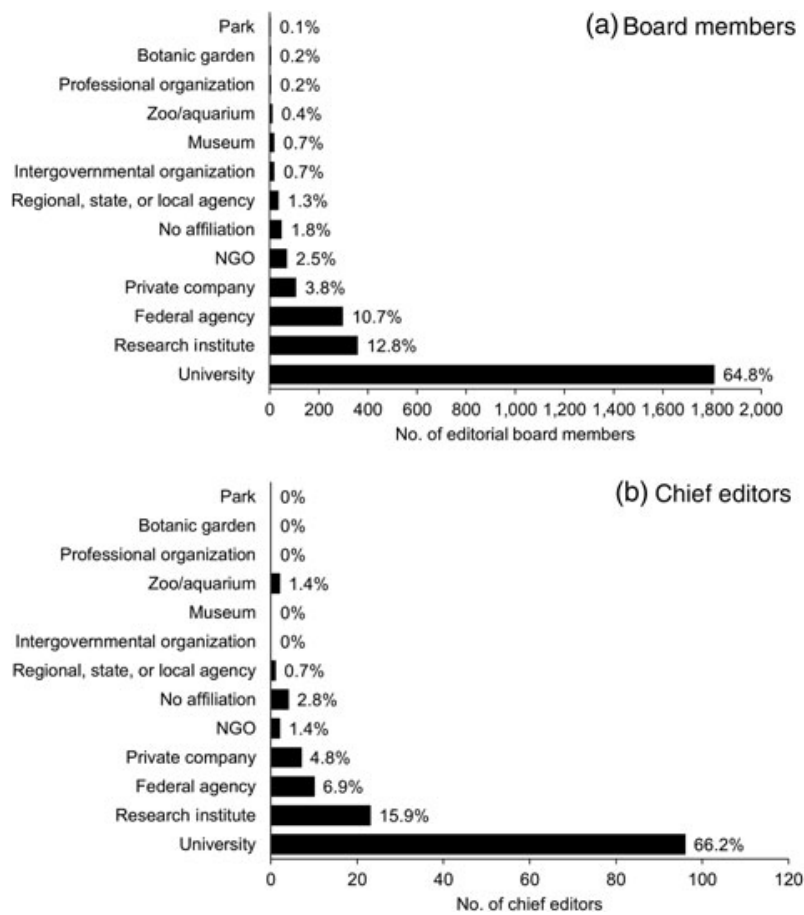

FIG. 2 Composition of (a) editorial board members $(n=2,793)$ and $(b)$ chief editors $(n=145)$ of applied natural resource journals, in terms of affiliation.

university, $16 \%$ with a research institution, $8 \%$ with a federal, regional, state or local agency, and $5 \%$ with private companies. Sixty-two percent of journals had at least one chief scientific editor who was not affiliated with a university.

Overall, $9 \%$ of editorial board members were affiliated with an agency or organization with responsibility for managing, regulating or setting policy for natural resources. Seventy-five percent of journals included at least one member affiliated with an agency or organization with management authority, but few journals (14\%) had a chief editor with management authority. Natural resource managers serving on editorial boards $(n=215)$ were most commonly 


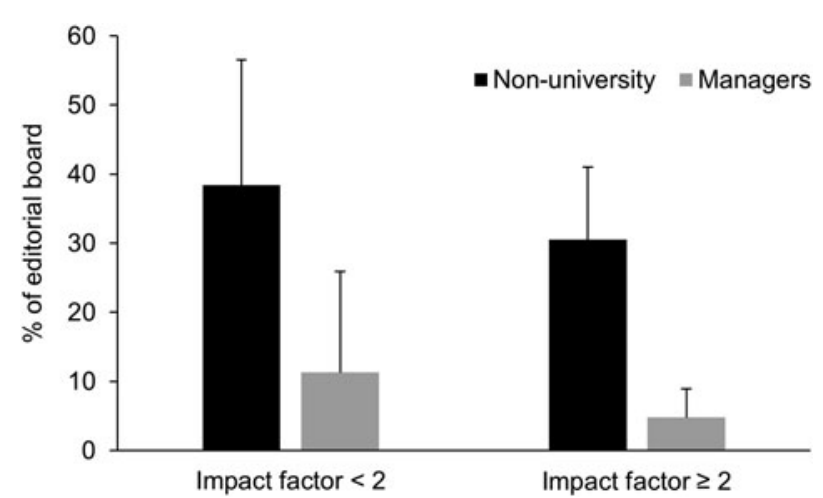

FIG. 3 Percentage of editorial boards ( \pm 1 SD) composed of non-university affiliates and natural resource managers for journals with impact factor $<2$ and journals with impact factor $\geq 2$.

affiliated with federal agencies (62\%), followed by regional/ state/local agencies (17\%), NGOs (10\%), intergovernmental organizations (9\%), and parks (2\%).

We found no significant difference with subject or impact factor category in the proportion of non-university affiliates (two-way ANOVA, $\mathrm{P}>0.28$ for main effects and interaction) or the proportion of managers on editorial boards (two-way ANOVA, P > 0.12 for main effects and interaction). However, this analysis did not include fisheries, limnology, oceanography, ornithology or zoology journals because of sample size limitations. Visual examination of the full dataset indicated some support for our hypothesis that areas of research with a more direct link to commercial harvest or applications (e.g. forestry, fisheries, entomology) and journals with lower impact factors (often having a more regional focus, congruent with the expertise of many managers) would have more managers on their editorial boards. Overall, representation of non-university affiliates and managers was slightly higher in journals with impact factors $<_{2}$ (Fig. 3), with substantial variability among subjects (Fig. 4; Supplementary Fig. S1). Ornithology, fisheries, forestry and plant sciences all had relatively high representation of natural resource managers $(\geq 17 \%)$. Most managers on the editorial boards of forestry and plant science journals represented federal agencies ( 85 and $75 \%$, respectively). Managers on the editorial boards of fisheries journals were split between federal and regional/state/local agencies ( 48 and $44 \%$, respectively), and managers on the editorial boards of ornithology journals were split between federal agencies and NGOs (53 and $41 \%$, respectively). Editorial boards of fisheries and ornithology journals also had a high representation of non-university affiliates (53\%; Fig. 3).

\section{Discussion}

We asked whether managers and policy makers are involved in making decisions about the articles published in

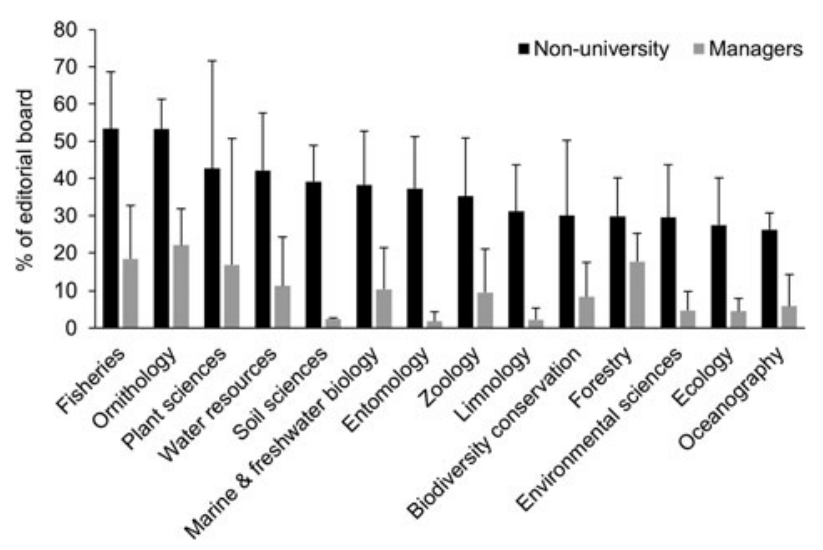

FIg. 4 Percentage of editorial boards $( \pm 1$ SD) in each subject category (Table 1) composed of non-university affiliates and natural resource managers.

conservation and applied natural resource journals. We found that nearly all editorial boards have at least one member from outside a university, and $75 \%$ include representation from agencies and organizations directly involved in managing natural resources. However, managers comprise a small proportion of the editorial boards of applied journals, regardless of impact factor, in most natural resource fields.

Although the overall representation of managers on editorial boards is low ( $9 \%)$, our findings indicate that it is possible to achieve substantial participation of non-university affiliates and of managers in the editorial process. Nearly $20 \%$ of journals across diverse fields (biodiversity conservation, entomology, environmental sciences, fisheries, marine and freshwater biology, ornithology, plant sciences, water resources) have editorial boards composed of $>50 \%$ nonuniversity affiliates. Similarly, $15 \%$ of journals from fields including biodiversity conservation, fisheries, forestry, marine and freshwater biology, ornithology, plant sciences, water resources and zoology have editorial boards composed of at least $20 \%$ managers. Furthermore, managers (including many local, state and regional managers) comprised $35 \%$ or more of the editorial boards of Bothalia, the North American Journal of Fisheries Management, and Lake and Reservoir Management. These fields (and individual journals) may serve as examples for others wishing to diversify their editorial boards and increase the participation of managers in the editorial review process.

Editorial board members from outside academia are most often from agencies and organizations operating at broad scales and/or without direct management authority (e.g. national agencies, research institutes). For example, the three U.S. agencies with the highest representation on editorial boards (U.S. Department of AgricultureAgricultural Research Service, U.S. Forest Service, U.S. Geological Survey) all operate at the federal level, and, of the three, only the U.S. Forest Service has management 
TABLE 1 Composition of editorial boards of applied natural resource journals.

\begin{tabular}{|c|c|c|c|c|c|c|c|c|c|c|}
\hline \multirow[b]{2}{*}{ Subject } & \multirow[b]{2}{*}{$\begin{array}{l}\text { No. of } \\
\text { journals } \\
\text { sampled }\end{array}$} & \multicolumn{9}{|c|}{ Proportion of editorial board } \\
\hline & & University & $\begin{array}{l}\text { Research } \\
\text { institute }\end{array}$ & $\begin{array}{l}\text { Federal } \\
\text { agency }\end{array}$ & $\begin{array}{l}\text { Regional, } \\
\text { state, or } \\
\text { local } \\
\text { agency }\end{array}$ & $\begin{array}{l}\text { Intergovern- } \\
\text { mental } \\
\text { organization }\end{array}$ & $\mathrm{NGO}^{*}$ & $\begin{array}{l}\text { Private } \\
\text { company }\end{array}$ & $\begin{array}{l}\text { Park, } \\
\text { museum, } \\
\text { zoo, or } \\
\text { botanic } \\
\text { garden }\end{array}$ & $\begin{array}{l}\text { No } \\
\text { affiliation }\end{array}$ \\
\hline $\begin{array}{l}\text { Biodiversity } \\
\text { conservation }\end{array}$ & 10 & 0.70 & 0.11 & 0.05 & 0.003 & 0.01 & 0.06 & 0.003 & 0.05 & 0.01 \\
\hline Ecology & 7 & 0.73 & 0.11 & 0.12 & 0.01 & 0 & 0.01 & 0.01 & 0.01 & 0 \\
\hline Entomology & 6 & 0.63 & 0.19 & 0.09 & 0 & 0 & 0.02 & 0.04 & 0.02 & 0.02 \\
\hline $\begin{array}{l}\text { Environmental } \\
\text { sciences }\end{array}$ & 10 & 0.71 & 0.09 & 0.06 & 0.01 & 0.003 & 0.04 & 0.08 & 0 & 0.02 \\
\hline Fisheries & 5 & 0.47 & 0.18 & 0.17 & 0.07 & 0.02 & 0.01 & 0.04 & 0 & 0.05 \\
\hline Forestry & 6 & 0.70 & 0.05 & 0.17 & 0.01 & 0.01 & 0.01 & 0.03 & 0 & 0.02 \\
\hline Limnology & 2 & 0.69 & 0.23 & 0.02 & 0.01 & 0 & 0 & 0.01 & 0 & 0.03 \\
\hline $\begin{array}{l}\text { Marine \& fresh- } \\
\text { water biology }\end{array}$ & 6 & 0.62 & 0.19 & 0.10 & 0.01 & 0.01 & 0.005 & 0.04 & 0 & 0.01 \\
\hline Oceanography & 2 & 0.74 & 0.05 & 0.01 & 0 & 0.03 & 0.01 & 0.10 & 0 & 0.05 \\
\hline Ornithology & 3 & 0.47 & 0.17 & 0.12 & 0 & 0.02 & 0.16 & 0.02 & 0.02 & 0.04 \\
\hline Plant sciences & 7 & 0.57 & 0.16 & 0.17 & 0.02 & 0 & 0.06 & 0.02 & 0.01 & 0.01 \\
\hline Soil sciences & 4 & 0.61 & 0.13 & 0.21 & 0 & 0.01 & 0 & 0.02 & 0.01 & 0.02 \\
\hline Water resources & 7 & 0.58 & 0.08 & 0.10 & 0.04 & 0.02 & 0.03 & 0.13 & 0.005 & 0.01 \\
\hline Zoology & 4 & 0.65 & 0.07 & 0.14 & 0.03 & 0 & 0.02 & 0.03 & 0.06 & 0.01 \\
\hline
\end{tabular}

${ }^{\star}$ Includes professional associations

authority. NGOs achieved the highest representation on editorial boards of ornithology journals $(16 \%)$, potentially reflecting the long history of NGOs dedicated to conducting research and conservation projects focused on birds (e.g. the Royal Society for the Protection of Birds, founded in 1889).

There are a number of possible reasons for our finding that managers comprise a relatively small proportion of the editorial boards of conservation and applied natural resource journals. Firstly, not having a postgraduate degree may make managers less attractive candidates for editorial board positions (however, a study found that $48 \%$ of natural resource managers in California, USA, had postgraduate degrees; Matzek et al., 2014). Furthermore, a substantial proportion of individuals who earn $\mathrm{PhDs}$ in zoology and environmental sciences are employed by federal (15\%) and state/local ( $7 \%)$ agencies, and private for-profit (16\%) and non-profit (6\%) organizations (NSF NCSES, 2013), suggesting that scientists with a strong research background may be found across a variety of sectors. Secondly, it may be difficult for practitioners to keep abreast of emerging research trends and methods, as more immediate work priorities often take precedence over research and publishing for those in policy and management positions (SKC and AHF, pers. obs.). Thirdly, values, motivations and reward structures differ between academic and resource management institutions, with the latter generally having shorter timeframes and broader political contexts in which contributions are evaluated, and less emphasis on publication of research results (Gibbons et al., 2008). As a result, managers may not have their supervisors' support to participate on editorial boards of scientific journals. Academic institutions have been encouraged to reward researchers for communication and collaboration with managers as a means to help bridge the research-implementation gap (Born et al., 2009; Arlettaz et al., 2010). We suggest that incentive structures that value and reward practitioners for participation in the research and publication process are equally important in management institutions and may lead to greater participation of managers in the editorial process.

Greater participation of managers in the editorial process could yield a number of benefits hypothesized to result from greater integration of managers into the overall research process. Research-based knowledge plays a critical role in decision making (Dicks et al., 2014), and peer-reviewed research articles and synthetic reviews in particular are highly valued by practitioners (Seavy \& Howell, 2010; Cook et al., 2012). Accordingly, increasing the participation of managers in the editorial review process could place a greater emphasis on, for example, increasing the number of published articles on topics that are relevant for management and include clear statements of the conservation, policy and management implications of the work (Schindler et al., 2011; Cvitanovic et al., 2014). Greater prevalence of managers 
on editorial boards could also promote a stronger focus on research evaluating the effectiveness of management and policy interventions. Currently, such evaluations are uncommon (Fazey et al., 2005) but they are an important factor in moving towards an evidence-based approach to conservation (Sutherland et al., 2004). Finally, editors who are managers may be more likely to invite other qualified managers to review submitted articles, producing a snowball effect. However, it remains to be studied whether increased participation of managers on editorial boards corresponds with increased management relevance of published articles or increased participation of managers in the peer review process. An evaluation of the management relevance of articles in applied natural resource journals with varying proportions of managers on their editorial boards would provide insight into the former. It will be more difficult to gauge the extent to which managers participate in the peer review process because the process is nearly always anonymous.

\section{Limitations}

We considered only the current affiliation of editors as an indicator of their awareness of the information needs of natural resource managers and policy makers. Some individuals (including both authors) currently at universities and other research-focused institutions work closely with or have previous experience as natural resource managers, which may give them a clearer perspective on the relevance of research topics for natural resource management and policy.

Also, we considered a relatively small number of journals that we defined as having an explicit focus on the application of research to natural resource conservation, management or policy. Other natural resource journals have an applied focus but did not meet the criteria for inclusion in our study. However, we have no reason to believe that the participation of managers on the editorial boards of these other journals would be higher than in the sampled journals.

\section{Conclusions}

There have long been calls for better integration of research and management activities in the field of natural resources (e.g. Prendergast et al., 1999; Sutherland et al., 2004; Sunderland et al., 2009). Many actions have been suggested to help bridge the divide, including establishing formal links and long-term relationships between research institutions and management agencies, early collaboration with managers in developing research projects, commitments by researchers to implement their research recommendations, open access publishing of research results and researcher sabbaticals in government agencies (Gibbons et al., 2008;
Milner-Gulland et al., 2010; Cook et al., 2013; Fuller et al., 2014; Campbell et al., 2015), and positive conservation outcomes have been reported (e.g. Arlettaz et al., 2010; Caudron et al., 2012; Lindenmayer et al., 2013). Natural resource journals are aware of the need to be more relevant for practice, and numerous journals have undertaken initiatives in support of this goal, including developing manuscript categories specifically targeting practitioners, focusing more on manuscripts that test management recommendations in the field, and providing open access to specific journal content (Meffe, 1998; Memmott et al., 2010; Milner-Gulland et al., 2010).

We evaluated the composition of editorial boards of conservation and applied natural resource journals, and found that although almost all editorial boards include at least one member from outside academia, resource managers represent only a small proportion of editorial boards. We suggest that one way to encourage journal content with increased relevance to managers and policy makers may be for research and management institutions to view the entire research and publication process as a shared responsibility, including representation of qualified scientists with a range of organizational affiliations outside academia (including agencies and organizations with management authority) in the editorial review process. Future studies should evaluate whether greater participation by managers in the editorial review process helps to bridge one aspect of the research-management gap by fostering publication of articles with greater relevance to natural resource conservation, management and policy.

\section{Acknowledgements}

This work was initiated while SKC was supported by National Science Foundation Integrative Graduate Education and Research Traineeship award DGE-1144752 (Novel ecosystems, rapid change, and no-analog conditions: the future of biodiversity conservation in humandominated landscapes) at the University of Wisconsin and AHF was employed by the Wisconsin Department of Natural Resources. We gratefully acknowledge this support. We thank Ramana Callan, the editor and two reviewers for helpful comments.

\section{References}

Arlettaz, R., Schaub, M., Fournier, J., Reichlin, T.S., Sierro, A., Watson, J.E.M. \& Braunisch, V. (2010) From publications to public actions: when conservation biologists bridge the gap between research and implementation. BioScience, 60, 835-842.

Born, J., Boreux, V. \& Lawes, M.J. (2009) Synthesis: Sharing ecological knowledge-the way forward. Biotropica, 41, 586-588.

Campbell, C.A., Lefroy, E.C., Caddy-Retalic, S., Bax, N., Doherty, P.J., Douglas, M.M. et al. (2015) Designing 
environmental research for impact. Science of the Total Environment, 534, 4-13.

Caudron, A., Vigier, L. \& Champigneulle, A. (2012) Developing collaborative research to improve effectiveness in biodiversity conservation practice. Journal of Applied Ecology, 49, 753-757.

Cook, C.N., Carter, R.W., Fuller, R.A. \& Hockings, M. (2012) Managers consider multiple lines of evidence important for biodiversity management decisions. Journal of Environmental Management, 113, 341-346.

Cook, C.N., Hockings, M. \& Carter, R.W. (2010) Conservation in the dark? The information used to support management decisions. Frontiers in Ecology and the Environment, 8, 181-186.

Cook, C.N., Mascia, M.B., Schwartz, M.W., Possingham, H.P. \& FulLER, R.A. (2013) Achieving conservation science that bridges the knowledge-action boundary. Conservation Biology, 27, 669-678.

Cvitanovic, C., Fulton, C.J., Wilson, S.K., van Kerkhoff, L., Cripps, I.L. \& MUthiga, N. (2014) Utility of primary scientific literature to environmental managers: an international case study on coral-dominated marine protected areas. Ocean \& Coastal Management, 102, 72-78.

Dicks, L.V., Walsh, J.C. \& Sutherland, W.J. (2014) Organising evidence for environmental management decisions: a ' $4 \mathrm{~S}$ ' hierarchy. Trends in Ecology \& Evolution, 29, 607-613.

Fayram, A.H., Schenborn, D.A., Hennessy, J.M., Nate, N.A. \& Schmalz, P.J. (2009) Exploring the conflict between broad scale and local inland fisheries management: the risks to agency credibility. Fisheries, 34, 232-236.

Fazey, I., Fischer, J. \& Lindenmayer, D.B. (2005) What do conservation biologists publish? Biological Conservation, 124, 63-73.

Fuller, R.A., Lee, J.R. \& Watson, J.E.M. (2014) Achieving open access to conservation science. Conservation Biology, 28, 1550-1557.

Gibbons, P., Zammit, C., Youngentob, K., Possingham, H.P., Lindenmayer, D.B., Bekessy, S. et al. (2008) Some practical suggestions for improving engagement between researchers and policy-makers in natural resource management. Ecological Management \& Restoration, 9, 182-186.

Gossa, C., Fisher, M. \& Milner-Gulland, E.J. (2015) The research-implementation gap: how practitioners and researchers from developing countries perceive the role of peer-reviewed literature in conservation science. Oryx, 49, 80-87.

Lindenmayer, D.B., MacGregor, C., Dexter, N., Fortescue, M. \& Cochrane, P. (2013) Booderee National Park management: connecting science and management. Ecological Management \& Restoration, 14, 2-10.

Matzek, V., Covino, J., Funk, J.L. \& SAunders, M. (2014) Closing the knowing-doing gap in invasive plant management: accessibility and interdisciplinarity of scientific research. Conservation Letters, 7 , 208-215.

Meffe, G.K. (1998) Conservation Biology: into the Millennium. Conservation Biology, 12, 1-3.

Memmott, J., Cadotte, M., Hulme, P.E., Kerby, G., Milner-Gulland, E.J. \& Whittingham, M.J. (2010) Putting applied ecology into practice. Journal of Applied Ecology, 47, 1-4.

Milner-Gulland, E.J., Fisher, M., Browne, S., Redford, K.H., Spencer, M. \& Sutherland, W.J. (2010) Do we need to develop a more relevant conservation literature? Oryx, 44, 1-2.

NSF NCSES (National Science Foundation, National Center for Science and Engineering Statistics) (2013)
Survey of Doctorate Recipients, 2013. Http://ncsesdata.nsf.gov/ doctoratework/2013/ [accessed 22 June 2015].

Prendergast, J.R., Quinn, R.M. \& Lawton, J.H. (1999) The gaps between theory and practice in selecting nature reserves. Conservation Biology, 13, 484-492.

Pullin, A.S. \& Knight, T.M. (2005) Assessing conservation management's evidence base: a survey of management-plan compilers in the United Kingdom and Australia. Conservation Biology, 19, 1989-1996.

Pullin, A.S., Knight, T.M., Stone, D.A. \& Charman, K. (2004) Do conservation managers use scientific evidence to support their decision-making? Biological Conservation, 119, 245-252.

Schindler, S., Curado, N., Nikolov, S.C., Kret, E., Cárcamo, B., Catsadorakis, G. et al. (2011) From research to implementation: nature conservation in the Eastern Rhodopes mountains (Greece and Bulgaria), European Green Belt. Journal for Nature Conservation, 19, 193-201.

Scott-Lichter, D. \& the Editorial Policy Committee, Council of Science Editors (2012) CSE's White Paper on Promoting Integrity in Scientific Journal Publications, 2012 Update, 3 rd revised edition. Council of Science Editors, Wheat Ridge, USA.

SeAvy, N.E. \& Howell, C.A. (2010) How can we improve information delivery to support conservation and restoration decisions? Biodiversity and Conservation, 19, 1261-1267.

Sullivan, P.J., Acheson, J.M., Angermeier, P.L., Faast, T., Flemma, J., Jones, C.M. et al. (2006) Defining and implementing best available science for fisheries and environmental science, policy, and management. Fisheries, 31, 460-465.

Sunderland, T., Sunderland-Groves, J., Shanley, P. \& CAmpbell, B. (2009) Bridging the gap: how can information access and exchange between conservation biologists and field practitioners be improved for better conservation outcomes? Biotropica, 41, 549-554.

Sutherland, W.J., Pullin, A.S., Dolman, P.M. \& Knight, T.M. (2004) The need for evidence-based conservation. Trends in Ecology \& Evolution, 19, 305-308.

Thomson Reuters (2013) ISI Web of Knowledge, Journal Citation Reports 2013 database. Http://webofknowledge.com [accessed 8 January 2015].

Walsh, J.C., Wilson, K.A., Benshemesh, J. \& Possingham, H.P. (2012) Unexpected outcomes of invasive predator control: the importance of evaluating conservation management actions. Animal Conservation, 15, 319-328.

\section{Biographical sketches}

SARAH CARTER's research interests focus on landscape and community ecology, and on prioritizing and evaluating the effectiveness of conservation plans and actions. She is particularly interested in strategies for bridging the gap between research, planning, management and policy in conservation and natural resource management. ANDREW FAYRAM is a quantitative fisheries biologist focusing on freshwater recreational fisheries, and an editor of Fisheries. Together the authors have more than 25 years of experience in natural resource policy, regulation and management, working for a state natural resource management agency (the Wisconsin Department of Natural Resources). 